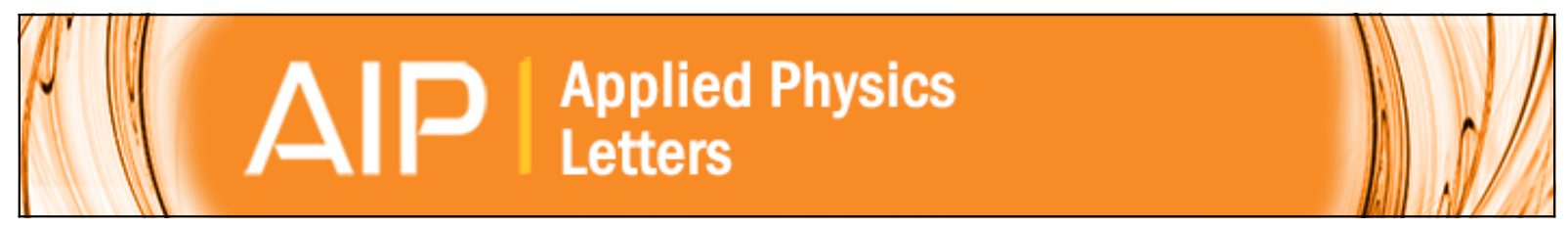

\title{
Reduction of hafnium oxide and hafnium silicate by rhenium and platinum
}

M. Copel, R. P. Pezzi, D. Neumayer, and P. Jamison

Citation: Applied Physics Letters 88, 072914 (2006); doi: 10.1063/1.2177360

View online: http://dx.doi.org/10.1063/1.2177360

View Table of Contents: http://scitation.aip.org/content/aip/journal/apl/88/7?ver=pdfcov

Published by the AIP Publishing

\section{Articles you may be interested in}

Temperature-dependent structural stability and optical properties of ultrathin $\mathrm{Hf}-\mathrm{Al}-\mathrm{O}$ films grown by facing-target reactive sputtering

J. Appl. Phys. 102, 094103 (2007); 10.1063/1.2802994

Metal-gate-induced reduction of the interfacial layer in $\mathrm{Hf}$ oxide gate stacks

J. Vac. Sci. Technol. A 25, 261 (2007); 10.1116/1.2435376

Temperature dependent defect formation and charging in hafnium oxides and silicates

J. Vac. Sci. Technol. B 23, 201 (2005); 10.1116/1.1850105

Thermal stability of the $\mathrm{HfO} 2 / \mathrm{SiO} 2$ interface for sub- $0.1 \mu \mathrm{m}$ complementary metal-oxide-semiconductor gate oxide stacks: A valence band and quantitative core-level study by soft $\mathrm{x}$-ray photoelectron spectroscopy

J. Appl. Phys. 96, 6362 (2004); 10.1063/1.1809769

Change in the chemical state and thermal stability of $\mathrm{HfO} 2$ by the incorporation of $\mathrm{Al} 2 \mathrm{O} 3$

Appl. Phys. Lett. 84, 571 (2004); 10.1063/1.1633976

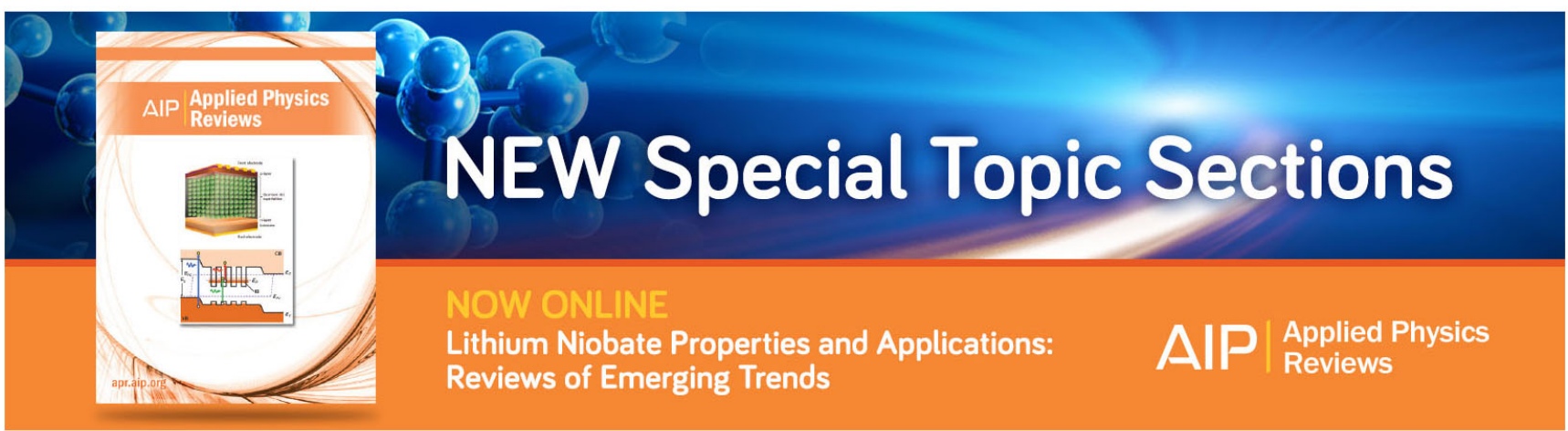




\title{
Reduction of hafnium oxide and hafnium silicate by rhenium and platinum
}

\author{
M. Copel, ${ }^{a}$ R. P. Pezzi, ${ }^{\text {b) }}$ D. Neumayer, and P. Jamison \\ IBM Research Division, T. J. Watson Research Center, P.O. Box 218, Yorktown Heights, New York 10598
}

(Received 16 August 2005; accepted 7 January 2006; published online 16 February 2006)

\begin{abstract}
We report chemical interactions of Hf-based dielectrics with Re and Pt overlayers during annealing. Reduction of the Hf to a suboxide is observed by $\mathrm{x}$-ray photoelectron spectroscopy, along with a decrease in total oxygen content measured by medium-energy ion scattering. For Re, this unanticipated reaction is highly dependent on the premetallization history of the sample. The presence of hydroxyl groups, observed by infrared absorption, is thought to be responsible. In addition, substantial electrostatic core-level shifts are observed, even in the absence of Hf reduction. The electrostatic shifts are symptomatic of altered threshold voltages for devices. (C) 2006 American Institute of Physics. [DOI: 10.1063/1.2177360]
\end{abstract}

Conventional Si complementary metal-oxidesemiconductor devices rely on polycrystalline-Si polysilicon as a gate conductor. An improvement in performance can be gained by replacing the polysilicon with a metal, eliminating the gate depletion effect. Metal gates are commonly used in conjunction with metal oxide gate dielectrics, such as $\mathrm{HfO}_{2}$ and $\mathrm{Hf}_{(1-x)} \mathrm{Si}_{x} \mathrm{O}_{2}$. This has the added advantage of avoiding unwanted polysilicon/ $/ \mathrm{HfO}_{2}$ interactions. ${ }^{1}$ For successful implementation, the gate metal must be chosen so that it does not undergo an unfavorable chemical interaction with the dielectric. Since the dielectric materials under consideration have been chosen based on thermodynamic stability, ${ }^{2}$ this leaves a wide variety of metals as eligible candidates. In particular, $p$-type metals with large work functions, such as $\mathrm{Pt}$ and $\mathrm{Re}$, are known to form relatively unstable oxides, and should be stable in contact with $\mathrm{HfO}_{2}$ and $\mathrm{SiO}_{2}$.

In this letter, we report unexpected chemical reactions between $\mathrm{Re}$ and $\mathrm{Pt}$ metallization layers and $\mathrm{HfO}_{2}$ and $\mathrm{Hf}_{(1-x)} \mathrm{Si}_{x} \mathrm{O}_{2}$ that lead to the reduction of Hf oxide to a suboxide. The reaction depends on the quality of the metal oxide, and does not take place for well-annealed metal oxides. Even in samples where no reduction of Hf is observed, substantial shifts are seen in the Hf $4 f$ and oxygen $1 s$ core level due to charged defects. The shifts are electrostatic rather than chemical in origin, and result in changes in the capacitancevoltage characteristics of devices.

The dielectrics used in this study were grown by chemical vapor deposition (CVD) from Hf tert-butoxide precursor on silicon oxynitride and introduced to an ultrahigh vacuum (UHV) analysis system after storage in air. Re was deposited in situ by electron-beam evaporation from a Ta crucible at a growth rate of about $1 \AA$ per minute. Pt was also deposited by e-beam evaporation, but in an external system. The oxidation state of the Hf was studied by x-ray photoelectron spectroscopy (XPS) using a $\mathrm{Mg} K \alpha$ source and an emission angle of $45^{\circ}$. Medium-energy ion scattering (MEIS) measurements were used to determine the oxygen content and morphology of films. All anneals were performed in the same UHV system as Re deposition, XPS, and MEIS.

\footnotetext{
${ }^{a)}$ Electronic mail: mcopel@us.ibm.com

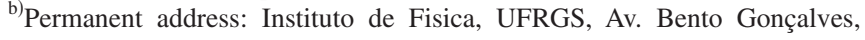
9500, Porto Alegre, RS, Brazil 91509-900.
}

First, let us examine the $\mathrm{Hf} 4 f$ core level of a $\mathrm{HfO}_{2}$ film that was briefly degassed at $200{ }^{\circ} \mathrm{C}$ prior to $\mathrm{Re}$ deposition (Fig. 1). The $4 f$ doublet appears at binding energies of 19.4 and $17.7 \mathrm{eV}$. This is typical of fully oxidized $\mathrm{Hf}\left(\mathrm{Hf}^{4+}\right)$. As the sample is postmetal annealed, a second Hf peak appears at a binding energy of $15.9 \mathrm{eV}$, which is indicative of $\mathrm{Hf}$ in a suboxide $\left(\mathrm{Hf}^{\mathrm{sub}}\right)$. (A larger shift of roughly $3.7 \mathrm{eV}$ would be expected for fully metallic Hf. It is likely that the peak labeled $\mathrm{Hf}^{\text {sub }}$ is in a partially oxidized configuration.) The intensity grows with further annealing. Judging from the relative intensity of the $\mathrm{Hf}$ peaks and the escape depth of photoelectrons, roughly $2-3 \AA$ of $\mathrm{HfO}_{2}$ is reduced. Similar behavior is found for Pt.

Reduction of $\mathrm{Hf}$ is found for both $\mathrm{HfO}_{2}$ and $\mathrm{Hf}_{(1-x)} \mathrm{Si}_{x} \mathrm{O}_{2}$ (Fig. 2). The amplitude of $\mathrm{Hf}^{\text {sub }}$ relative to $\mathrm{Hf}^{4+}$ is somewhat smaller for $\mathrm{Hf}_{(1-x)} \mathrm{Si}_{x} \mathrm{O}_{2}$ than $\mathrm{HfO}_{2}$, but shows the same trend, increasing for temperatures greater than $550{ }^{\circ} \mathrm{C}$. Evidently, the incorporation of $\mathrm{SiO}_{2}$ into $\mathrm{HfO}_{2}$ offers only minor stabilization to $\mathrm{Hf}_{(1-x)} \mathrm{Si}_{x} \mathrm{O}_{2}$ in contact with Re.

Using MEIS, we observe a decrease in the oxygen content of the film when the $\mathrm{HfO}_{2}$ is reduced by Re. A slight

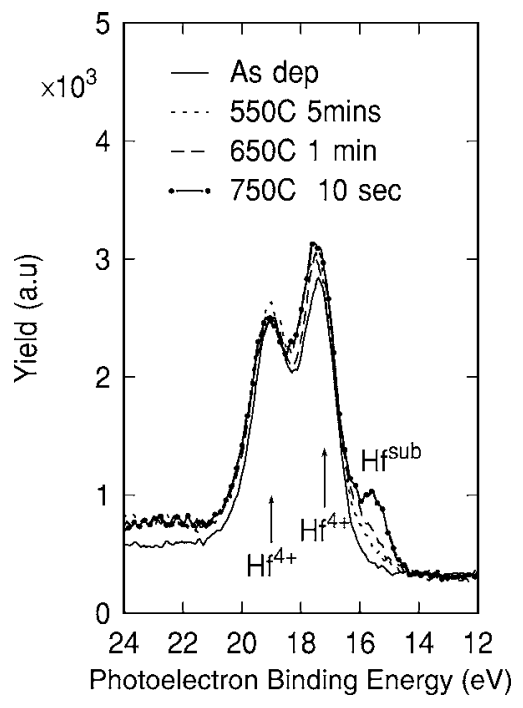

FIG. 1. X-ray photoemission spectra of Re metallized $\mathrm{HfO}_{2} / \mathrm{SiO}_{x} \mathrm{~N}_{y} / \mathrm{Si}$ samples with various postmetal anneals. The Hf $4 f$ peaks are shown. Positions for oxidized $\mathrm{Hf}\left(\mathrm{Hf}^{4+}\right)$ and $\mathrm{Hf}$ suboxide $\left(\mathrm{Hf}^{\text {sub }}\right)$ are indicated. A peak due to Hf suboxide grows with increasing annealing temperature. 


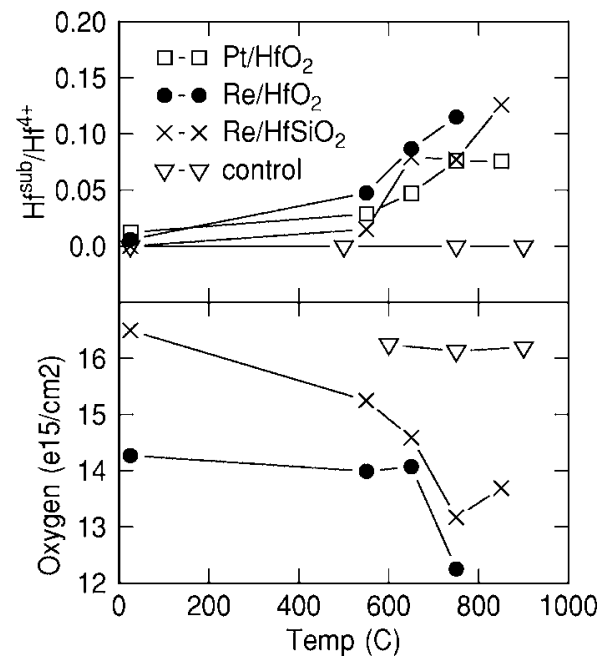

FIG. 2. Relative intensity of partially oxidized $\mathrm{Hf}\left(\mathrm{Hf}^{\mathrm{sub}}\right)$ normalized to fully oxidized $\mathrm{Hf}\left(\mathrm{Hf}^{4+}\right)$ detected by x-ray photoemission (top). The total oxygen content of the film measured MEIS decreases as the $\mathrm{Hf}^{\text {sub }}$ signal increases (bottom). Results are shown for Re and Pt metallized $\mathrm{HfO}_{2}$ and Re metallized $\mathrm{Hf}_{(1-x)} \mathrm{Si}_{x} \mathrm{O}_{2}$ as well as uncapped $\mathrm{HfO}_{2}$.

increase in oxygen appears above $900{ }^{\circ} \mathrm{C}$, but we believe it is not significant. The drop in oxygen intensity shows that oxygen is lost from the sample, rather than merely transferred to the Re. Furthermore, the Re $4 f$ core level shows no evidence of oxidation (not shown), although some low concentration of oxygen could remain dissolved in the Re. It is noteworthy that samples without Re showed no oxygen loss between $600{ }^{\circ} \mathrm{C}$ and $950{ }^{\circ} \mathrm{C}$, indicating that uncapped $\mathrm{HfO}_{2} / \mathrm{SiO}_{x} \mathrm{~N}_{y} / \mathrm{Si}$ structures are stable in the temperature regime relevant to device processing. (Ultimately, at higher temperatures, the $\mathrm{HfO}_{2}$ will react with the underlying substrate to form a silicide, as has been observed for $\mathrm{ZrO}_{2}$ and $\mathrm{HfO}_{2}$ samples without a Re overlayer. $)^{3-5}$

So far, we have only discussed films that have undergone minimal thermal cycling prior to deposition. Much different results are found for Re metallization of films that have been densified by in situ UHV anneals (Fig. 3). A 5 min premetal anneal at $500{ }^{\circ} \mathrm{C}$ strongly suppresses the formation of the

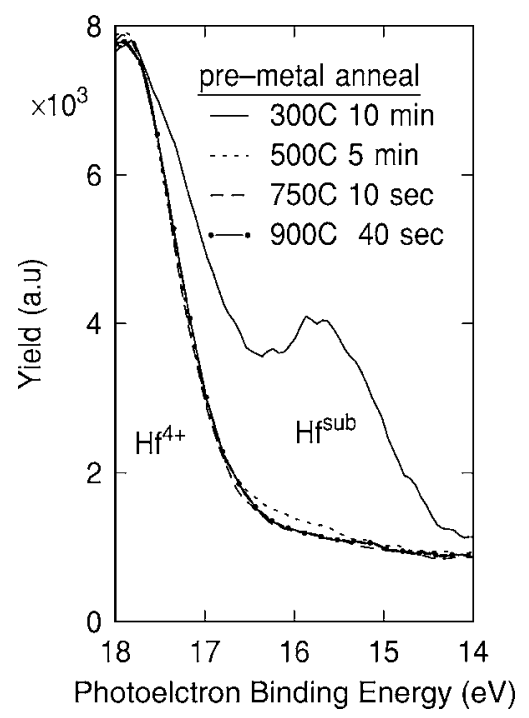

FIG. 3. Effect of premetal anneal on reactivity of $\mathrm{HfO}_{2}$ with Re. After metallization all samples received a $10 \mathrm{~s} 850^{\circ} \mathrm{C}$ anneal in UHV. The reactivity is reduced by a premetal anneal.

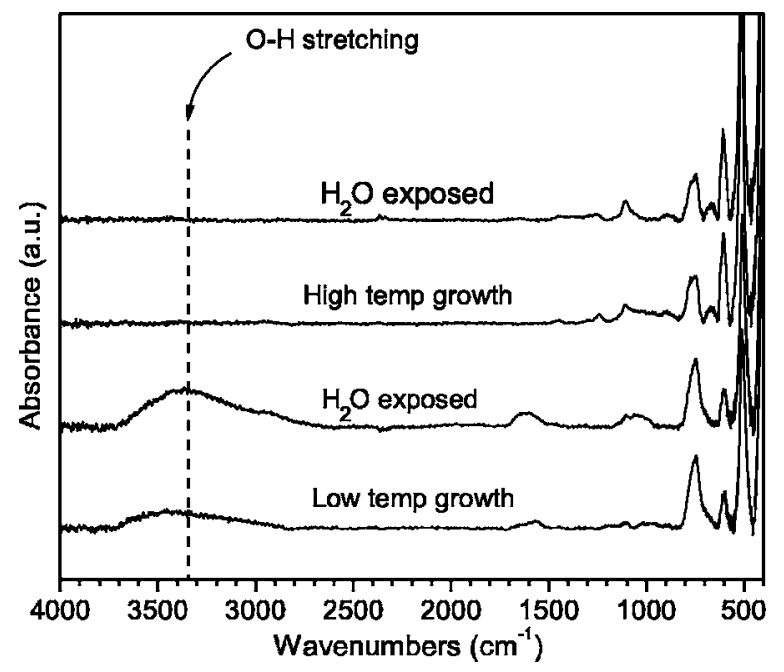

FIG. 4. Infrared absorption spectra for $\mathrm{HfO}_{2}$ films grown at various temperatures and the effect of $\mathrm{H}_{2} \mathrm{O}$ exposure. The feature at $3365 \mathrm{~cm}^{-1}$ is assigned to $\mathrm{O}-\mathrm{H}$ stretching.

$\mathrm{Hf}^{\text {sub }}$ during postmetal annealing. A sample that has been preannealed at $750{ }^{\circ} \mathrm{C}$ for $10 \mathrm{~s}$ shows no detectable $\mathrm{Hf}^{\text {sub }}$ signal. From this, we can conclude that reduction of preannealed $\mathrm{HfO}_{2}$ by Re is below the detection level of XPS.

Significant changes take place in $\mathrm{HfO}_{2}$ during premetal annealing that may explain differences in the reactivity. It is likely that the combination of impurity elimination and crystallization improves the resistance of $\mathrm{HfO}_{2}$ to oxygen removal. Crystallization has been observed at high temperatures, ${ }^{6}$ and it is likely that an amorphous or highly defective film will have both greater hydroxyl uptake as well as susceptibility to chemical attack. Some evidence of carbonates has been found in $\mathrm{HfO}_{2}$ films ${ }^{7}$ and hydroxyls have been found in $\mathrm{Y}_{2} \mathrm{O}_{3} .{ }^{8}$ To clarify the role of impurities, samples were exposed to $\mathrm{H}_{2} \mathrm{O}$ by immersion for $24 \mathrm{~h}$ at room temperature prior to Re deposition. This was found to significantly increase suboxide formation, compared to storage in a dry ambient. Thus, we believe that hydroxyl groups are mainly responsible for the instability.

Direct evidence of hydroxyl groups was found in $1000 \AA$ thick CVD $\mathrm{HfO}_{2}$ films by infrared absorption spectroscopy (IRAS) (Fig. 4). For low-temperature growth, where poorer crystallinity is expected, a broad hydroxyl peak was observed centered at $3365 \mathrm{~cm}^{-1}$. In addition, the hydroxyl intensity increased with $\mathrm{H}_{2} \mathrm{O}$ exposure by immersion. On the other hand, no hydroxyl peak is observed on films grown at higher temperature, even after exposure to $\mathrm{H}_{2} \mathrm{O}$. This demonstrates that hydroxyl uptake can take place in $\mathrm{HfO}_{2}$, and that the extent depends on the details of film deposition. Since hydroxyls will desorb during premetal annealing, they are likely to be greatly reduced in densified samples. Thus, the IRAS results are in keeping with the observation that preannealed films are less susceptible to chemical reaction with $\mathrm{Re}$.

The reduction of $\mathrm{HfO}_{2}$ is not anticipated by thermodynamic considerations. The reaction of $\mathrm{HfO}_{2}$ with a noble metal $(\mathrm{Me})$

$$
\mathrm{HfO}_{2}+\mathrm{Me} \rightarrow \mathrm{HfO}_{2-x}+\mathrm{MeO}_{x}
$$

should not occur, since the formation energy of $\mathrm{HfO}_{2}$ is greater than that of Re or Pt oxide. Alternatively, we may 


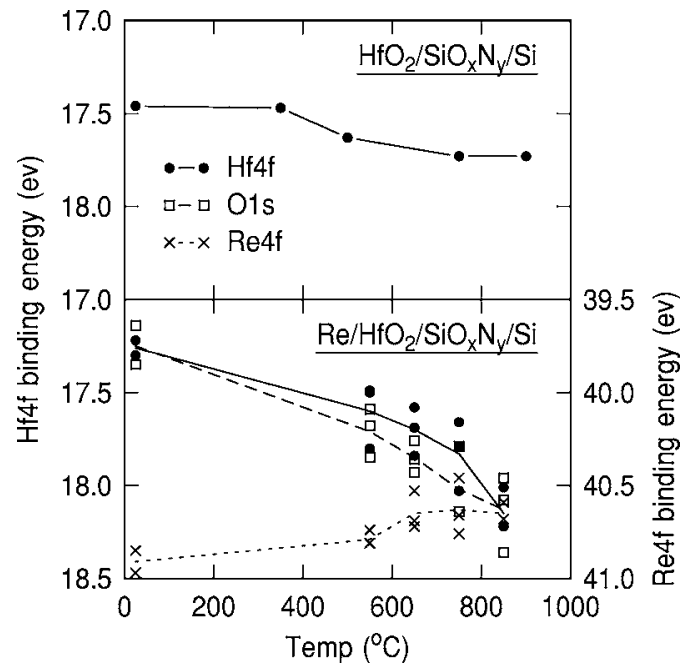

FIG. 5. Effect of annealing on core-level binding energies of $\mathrm{HfO}_{2}$ samples. An uncapped sample (top) shows a much reduced shift compared to Re capped samples (bottom). For the Re capped samples, the Re $4 f$ and oxygen $1 s$ binding energies are also shown. The oxygen $1 s$ binding energy has been shifted to allow plotting on the same scale.

consider the catalytic decomposition of $\mathrm{HfO}_{2}$ with additional OH impurities:

$$
\mathrm{HfO}_{2} \mathrm{H}_{2 x}+\mathrm{Me} \rightarrow \mathrm{HfO}_{2-x}+\mathrm{Me}+\mathrm{xH}_{2} \mathrm{O} \uparrow .
$$

In this case, not only is the $\mathrm{HfO}_{2}$ destabilized by the presence of $\mathrm{OH}$, but we also have the possibility that the presence of Re may assist in $\mathrm{HfO}_{2}$ decomposition by stabilizing the formation of charged oxygen vacancies. Since both $\mathrm{Re}$ and $\mathrm{Pt}$ have large work functions, they can act as a sink for electrons thereby lowering the formation energy of charged defects. ${ }^{9,10}$ Even in samples which have been thoroughly preannealed we still see indirect (electrostatic) evidence of charged defects. This suggests that some level of oxygen vacancy formation takes place even without hydroxyl groups present.

Indirect evidence of charged defects can be observed by electrostatic shifts in XPS. In the spectra shown so far, the binding energy has been shifted to align the $\mathrm{Hf}^{4+}$ peaks. Binding energy shifts during postmetal anneals are observed for both the Hf $4 f$ and oxygen $1 s$ core lines on Re metallized samples that have been preannealed to avoid detectable reduction of the $\mathrm{HfO}_{2}$ (Fig. 5). Both core levels shift by 0.7 to $0.8 \mathrm{eV}$ toward higher binding energy after postmetal anneals to $850{ }^{\circ} \mathrm{C}$. At the same time, the Re $4 f$ core level undergoes a much smaller change of 0.2 to $0.3 \mathrm{eV}$ toward lower binding energy. The Re shift is most likely due to agglomeration of the metal, which is observed with MEIS. This allows us to rule out sample charging as the origin of the shifts. Electrostatic shifts have previously been reported for uncapped $\mathrm{HfO}_{2}$ layers, ${ }^{11}$ with a larger magnitude, but the same direction. In Ref. 11, the shifts were attributed to excess oxygen in the metal oxide. We observe only 0.3 to $0.4 \mathrm{eV}$ shifts in uncapped samples. We believe that the larger metal-induced shifts have a different origin, described below.

Significant shifts in threshold voltages have been observed for $p$-type metal/ $/ \mathrm{HfO}_{2}$ structures annealed in reducing ambients, ascribed to dangling $\mathrm{Hf}$ bonds ${ }^{12}$ or oxygen vacancies. $^{9,10,13}$ In light of this, we suggest the following interpretation of electrostatic shifts of the metal-oxide core levels. On samples capped with high work function metals, creation of charged defects near the metal/dielectric interface is highly facile, and the Fermi level is driven from its initial position near the valence band toward the conduction band. This is observed as a shift of the Hf $4 f$ and oxygen $1 s$ levels toward greater binding energy. Indeed, capacitance-voltage data for preannealed samples confirm that there is significant movement of the Fermi level after an $850{ }^{\circ} \mathrm{C}$ postmetal anneal in UHV. These results are supported by Fermilevel measurements using pulsed laser photoemission spectroscopy. ${ }^{14}$

In summary, two types of interactions are observed for Re metallized $\mathrm{HfO}_{2} / \mathrm{SiO}_{x} \mathrm{~N}_{y} / \mathrm{Si}$ structures. On air exposed samples, chemical reduction of the Hf takes place during postmetal annealing in UHV. The instability is enhanced by the presence impurities, most likely hydroxyls. In addition, we observe significant electrostatic shifts due to charged defects, tentatively thought to be oxygen vacancies.

The authors thank A. Ellis and M. C. Reuter for technical assistance, and S. Guha, E. Cartier, and R. Haight for helpful discussions.

${ }^{1}$ C. Hobbs, L. Fonseca, A. Knizhik, V. Dhandapani, S. B. Samavedam, W. J. Taylor, J. P. Grant, L. G. Dip, D. H. Triyoso, R. I. Hegde, D. Gilmer, R. Garcia, D. Roan, L. Lovejoy, R. Rai, L. Hebert, H. Tseng, B. White, and P. Tobin, IEEE Trans. Electron Devices 51, 971 (2004).

${ }^{2}$ K. J. Hubbard and D. G. Schlom, J. Mater. Res. 11, 2757 (1996).

${ }^{3}$ M. Copel, M. Gribelyuk, and E. Gusev, Appl. Phys. Lett. 76, 436 (2000).

${ }^{4}$ H. Watanabe and N. Ikarashi, Appl. Phys. Lett. 80, 559 (2002).

${ }^{5}$ S. Sayan, E. Garfunkel, T. Nishimura, W. H. Schulte, T. Gustafsson, and G. D. Wilk, J. Appl. Phys. 94, 928 (2003).

${ }^{6}$ E. P. Gusev, C. Cabral, Jr., M. Copel, C. D’Emic, and M. Gribelyuk, Microelectron. Eng. 69, 145 (2003).

${ }^{7}$ T. Gougousi, D. Niu, R. W. Ashcraft, and G. N. Parsons, Appl. Phys. Lett. 83, 3543 (2003).

${ }^{8}$ D. Niu, R. W. Ashcraft, and G. N. Parsons, Appl. Phys. Lett. 80, 3575 (2002).

${ }^{9}$ K. Shiraishi, K. Yamada, K. Torii, Y. Akasaka, K. Nakajima, M. Konno, T. Chikyow, H. Kitajima, and T. Arikado, Jpn. J. Appl. Phys., Part 2 43, L1413 (2004).

${ }^{10}$ S. Guha and F. R. McFeely (private communication).

${ }^{11}$ C. C. Fulton, G. Lucovsky, and R. J. Nemanich, Appl. Phys. Lett. 84, 580 (2004).

${ }^{12}$ J. K. Schaeffer, L. R. C. Fonseca, S. B. Samavedam, Y. Liang, P. J. Tobin, and B. E. White, Appl. Phys. Lett. 85, 1826 (2004).

${ }^{13}$ E. Cartier, F. R. McFeely, V. Narayanan, P. Jamison, B. P. Linder, M. Copel, V. K. Paruchuri, V. S. Basker, R. Haight, D. Lim, R. Carruthers, T. Shaw, M. Steen, J. Sleight, J. Rubino, H. Deligianni, S. Guha, R. Jammy, and G. Shahidi, VLSI Symp. Proc. 2005, 230.

${ }^{14}$ G. Lim, R. Haight, M. Copel, and E. Cartier, Appl. Phys. Lett. 87, 072902 (2005). 